\title{
Trabalho e educação na atualidade: mediações com a Educação Física brasileira
}

\author{
Work and education in the present: mediations with brazilian Physical \\ Education
}

Hajime Takeuchi Nozaki*

Universidade Federal de Juiz de Fora

Resumo O objetivo do artigo é apresentar as discussões que permeiam o campo trabalho e educação no Brasil e analisar a sua interlocução com a produção no campo da Educação Física. Para tal, realizou um estado da arte das pesquisas do trabalho do professor de Educação Física.Tais estudos são mediados pela discussão em torno dos campos de atuação, sendo possível identificar duas grandes linhas, a da escola e a dos campos não escolares. Nos estudos dos campos não escolares, há uma predominância das academias de ginástica, investigando a gestão empresarial e o trabalho do professor. Os estudos do campo escolar referem-se, essencialmente, ao trabalho pedagógico da educação física. A importante contribuição destes estudos está na compreensão do objeto do trabalho do professor de Educação Física em uma totalidade concreta.

PAlAVRAs-Chave: Trabalho, Educação Física, Estado da arte.

\begin{abstract}
The aim of this paper is to present the discussions of work and education in Brazil and to analyze their interaction with the production in the field of physical education. The study place a state of the art ofstudies about work of the physical education teacher. Such studies are mediated by the discussion of the fields, and it is possible to identify two broad lines, the school and non-school fields. In studies of non-school fields, there is a predominance of gyms, investigating corporate management and the work of the teacher. The studies about school refers primarily to the work of teaching physical education. The important contribution of these studies is the understanding of the purpose of the physical education teacher in a concrete totality.
\end{abstract}

KEYWORDS: Work, Physical Education, State of the art. 


\section{Introdução}

Os estudos sobre as mudanças no mundo do trabalho e suas mediações com a educação física brasileira têm se evidenciado há uma década. Por sua vez, tais estudos têm se apoiado em outros do campo trabalho e educação, na área educacional, que têm sido cada vez mais foco de atenção por parte da educação física brasileira. Neste sentido, trata-se de um importante esforço teórico investigar as mediações entre estes dois campos de estudo, analisando o avanço da produção científica da educação física brasileira, no que tange às discussões afetas às mudanças no mundo do trabalho.

Assim, o objetivo deste artigo é apresentar as discussões que permeiam o campo trabalho e educação no Brasil e analisar a sua interlocução com a produção no campo da educação física. Para tal, será realizado um estado da arte das pesquisas do trabalho do professor de educação física. Algumas questões se tornaram norteadoras deste texto: a) como se formou e o que discute o campo trabalho e educação?; b) qual a sua base teórica?; c) como dialoga este campo de estudos com a educação física?; d) quais são as principais contribuições dos estudos do trabalho do professor de educação física?; e) é possível afirmar a constituição de um novo campo de estudos ou a tendência de sua formação na educação física?

Para a elaboração deste estudo, foram revisados os principais textos do campo trabalho e educação. Também foram revisados teses, dissertações, monografias e artigos com a temática do trabalho na educação física. A exposição deste estudo foi dividida em três partes: a primeira apresenta o surgimento do campo trabalho e educação no Brasil e as suas principais discussões na contemporaneidade; a segunda expõe as contribuições deste campo para a educação física brasileira, e a terceira elabora um estado da arte dos estudos sobre o trabalho e a educação física, avaliando a formação de um novo campo de estudo.

\section{Surgimento do campo trabalho e educação e principais discussões na contemporaneidade ${ }^{1}$}

O campo trabalho e educação foi formado, no Brasil, a partir dos estudos críticos de outra disciplina acadêmica, a economia da educação. Desde o final da II Guerra Mundial, na década de 1950, no contexto de recomposição da economia capitalista, a economia burguesa empenhava-se, por um lado, em reconstruir estratégias de gerência da crise do capital e, por outro, na redistribuição da divisão internacional do trabalho, que seria liderada, pela primeira vez na história, pelos EUA. Sob o ponto de vista da ajuda norte-americana à Europa, destaca-se o plano Marshall, que deslocou um grande fluxo de capitais, necessitando, por outro lado, de uma mão de obra especializada. Neste ponto que Bazílio (1993) avalia que a educação, que sempre figurava como uma despesa do Estado capitalista, começou a tomar a proporção de investimento.

A principal tese no campo econômico que justificava os investimentos em educação é de Schultz, professor do departamento de economia da Universidade de Chicago, que estudou os ganhos de produtividade gerados pelo assim chamado fa- 
tor humano na produção, determinando o que chamou ser "o valor econômico da educação" (SCHULTZ, 1967). Sua tese, denominada de Teoria do Capital Humano (TCH), rendeu-lhe um prêmio Nobel de economia e baseava-se na ideia de que os investimentos em educação trariam aumentos reais na produtividade. Assim, aquelas pessoas que investissem em sua educação alcançariam maiores patamares sociais, bem como os países que assim o fizessem avançariam no seu desenvolvimento econômico (FRIGOTTO, 1995).

Estava lançada uma questão que originaria as discussões do campo trabalho e educação: a relação entre a educação e a produção capitalista. A década de 1970, no Brasil, foi fecunda no que diz respeito à crítica à TCH. Sob os auspícios do desenvolvimentismo econômico do regime militar, baseado na pesada entrada de investimentos internacionais e grande aumento da dívida externa do país, a educação passou por várias reformas desde o final da década de 1960, ampliando a rede de ensino, remodelando a educação profissional e superior, obedecendo à divisão internacional do trabalho e aprofundando a dualidade estrutural da educação. Neste contexto, uma crítica importante foi a tese de doutorado de Wagner Rossi. Suas principais análises eram de que a expansão das oportunidades educacionais nada diminui as diferenças socioeconômicas e que a educação legitimaria o fracasso para as classes sociais dominadas. Assim, o papel da escola seria o de formar mão de obra servil ao capital (BAZÍLIO, 1993). A crítica de Rossi (1980), comum a outros autores tais como Galvan (1979) e Freitag (1986), concluía que a educação, portanto, potenciaria o trabalho, gerando uma maior produtividade que, contudo, aprofundaria a mais-valia retirada do trabalhador pelo capital.

A formulação de Rossi recebeu crítica, agora em 1980, de outra tese, feita por Salm (1980). Para ele, há um limite nas análises dos autores anteriores, posto que estabeleciam a mesma relação linear entre produção e escola elaborada pela TCH. Já Salm (1980) avalia que o capital prescinde da escola para formar sua mão de obra, posto que esta seria formada, essencialmente, no próprio ambiente de trabalho, no interior do processo produtivo. Assim, a escola não seria responsável pela qualificação dos trabalhadores para o processo produtivo, tornando-se improdutiva para o capital.

$\mathrm{Na}$ sequência, a tese de Frigotto, de 1985, veio a sintetizar e superar as duas posições críticas à TCH. O exame da questão central em debate, a relação entre educação e produção capitalista, foi realizado considerando a mediação histórica da luta de classes e o processo educacional no país. Frigotto (1989) apoiou-se no conceito de dualidade estrutural da educação, que lhe proporcionou a reflexão de que não existe, na concreticidade, uma única escola, abstrata, mas duas escolas, conforme a formação da sociedade classista. Para a formação dos gestores do capital ou da tecnocracia estatal, a escola cumpriria funções de caráter geral. Contudo, a escola em debate seria aquela que formaria os filhos da classe trabalhadora que, historicamente, lutam pela ampliação do acesso escolar. Haveria no capitalismo uma contradição: ao mesmo tempo que pretende negar o conhecimento socialmente produzido, necessita formar minimamente os trabalhadores que, por sua vez, lutam para buscar maiores patamares educacionais. Neste ponto, a desqualificação da escola para os trabalhadores não deve ser vista como uma resultante das falhas ou da incompetência, mas como a própria mediação que ela 
efetiva no interior do capitalismo. Assim: "Trata-se de uma desqualificação orgânica, uma 'irracionalidade racional', uma 'improdutividade produtiva', necessária à manutenção da divisão social do trabalho e, mais amplamente, à manutenção de sociedade de classes" (FRIGOTTO, 1989, p. 180).

No ano seguinte, em 1986, Kuenzer trouxe a público o seu estudo sobre as relações educativas no interior do processo produtivo, ou seja, a organização do processo educativo em uma fábrica do Paraná, o que denominou de "a pedagogia da fábrica”, conforme intitulou o seu texto (KUENZER, 1986). Talvez seja justo afirmar que a tese da "improdutividade da escola produtiva" representa, junto com o exame da "pedagogia da fábrica", um marco para o campo de estudos que ficou, inicialmente, conhecido como educação e trabalho e, posteriormente, trabalho e educação. A inversão destes dois termos obedeceu à própria referência teórica deste campo, que compreende o trabalho como categoria central da existência humana e princípio educativo emancipador.

O marxismo foi se destacando como o referencial teórico que se tornou hegemônico ao longo da formação do campo trabalho e educação. Desde as primeiras formulações críticas de Rossi, Galvan e Freitag à TCH, é possível notar o que Frigotto (1989) denominou de um "apelo à Marx" (p. 136). Já Bazílio (1993) destaca o caráter crítico-reprodutivista destas formulações, "fruto do pensamento pedagógico hegemônico na década de 70, onde são determinantes as contribuições de Bourdieu e Passeron" (p. 21). Por outro lado, também Salm apoiou-se no marxismo para realizar crítica à vinculação imediata entre processo produtivo e educativo, presente no grupo de autores anteriores (FRIGOTTO, 1989). Já Frigotto avançou teoricamente ao lançar mão da categoria da mediação para compreender que a educação, situada na superestrutura capitalista, mantém relações não só ideológicas, mas também ocupa seu lugar no sistema de produção de mercadorias, ao tornar a escola um lugar de improdutividade para a classe trabalhadora.

A esta altura, o marxismo se consolidou enquanto teoria central para o campo trabalho e educação, propondo uma análise do processo educacional mediado pela totalidade das relações sociais de produção, considerando seus processos históricos de contradição. É igualmente justo afirmar que a consolidação do marxismo, no campo trabalho e educação, obedeceu a um movimento mais geral, de consolidação desta própria teoria no campo educacional, sobretudo com as contribuições de Saviani (1985), na construção da pedagogia histórico-crítica, que destacava o importante papel do movimento da contradição, no seio da escola capitalista. Por sua vez, o próprio crescimento do referencial marxista obedeceu a um contexto mais amplo da sociedade brasileira da década de 1980, de redemocratização da política e surgimento de movimentos sociais organizados e partidos políticos de esquerda no país.

As contribuições do campo trabalho e educação, na contemporaneidade, referem-se ao exame das relações de produção capitalista e as demandas criadas no campo da formação humana. De outro modo, dedica-se aos estudos da formação humana que supere aquela do campo do capital, entre eles a pedagogia socialista, a politecnia ou a formação omnilateral. ${ }^{2}$ 
A economia política, área de nascimento do marxismo, bem como a sociologia do trabalho, tornam-se as disciplinas que mais dialogam com o campo trabalho e educação para a reflexão da formação humana no capitalismo contemporâneo. Neste sentido, tornam-se base e referência das análises sobre a estrutura e conjuntura da crise do capital na década de 1970, o qual ocasionou uma série de mudanças nas estratégias econômicas, políticas e sociais - inclusa a educação - das sociedades, tanto do capitalismo central quanto do periférico, caso do Brasil. São tomados como base os estudos que convergem nas análises de que a falência do padrão de acumulação tayloristafordista e do Estado de bem-estar social e a chegada, posteriormente, do padrão de acumulação toyotista e do neoliberalismo, tratam-se de formas gerenciais da crise do capital. Neste ponto, são contemplados autores tais como Bihr (1998), Harvey (1992), Alves (2000), Anderson (1995) Antunes (1999), Gounet (1999), entre outros.

As consequências da gerência da crise para a classe trabalhadora são estudada em um duplo aspecto, sob o ponto de vista das mudanças nas suas condições de trabalho e no que diz respeito às mudanças em sua formação e qualificação para o trabalho. As modificações do novo mundo do trabalho implicam no aumento do desemprego e do subemprego, na precarização, flexibilização e intensificação do trabalho. Autores tais como Vasapollo (2005), Pochmann (1999, 2001), Singer (2000), junto com os demais citados, conferem materialidade para as análises sobre a complexificação da classe trabalhadora (ANTUNES, 1995, 1999) e o trabalho atípico (VASAPOLLO, 2005) na contemporaneidade. Por outro lado, há a necessidade da formação do trabalhador de novo tipo para atender as demandas criadas pela nova forma de organização do trabalho, o toyotismo.

Assim, os estudos do trabalho e educação voltam-se para a investigação da formação do trabalhador polivalente e flexível, que atende às novas demandas do capital. Neste particular, a atenção é dada para o sistema de competências, enquanto nova pedagogia do capital. A formação das competências passaria, portanto, desde os projetos provenientes do setor produtivo, quanto no próprio reordenamento da política educacional brasileira dos anos 1990. Destacam-se no estudo desta temática Rodrigues (1998), Ramos (2001), Manfredi (1999), Rummert (1998), entre outros.

Se a produção do campo trabalho e educação esforça-se em mapear o projeto hegemônico de formação humana do capital, por outro lado, também se dedica aos estudos voltados para a formação contraposta ao capital, no campo socialista. Nesta discussão, observam-se duas características interessantes: o aprofundamento dos estudos no interior do referencial marxista e uma polêmica com relação a conceitos, terminologias e perspectivas, emanadas no interior deste mesmo referencial. Uma característica comum a estes estudos é o aprofundamento da categoria trabalho, desde os textos de Marx e Engels. Lukács também é um autor de base para o aprofundamento desta categoria. Já Gramsci é recorrido para tratar do trabalho enquanto princípio educativo (SAVIANI, 2003).

Contudo, os autores do trabalho e educação divergem com relação aos conceitos e termos utilizados. Tumolo $(2003,2005)$ contesta que o trabalho como princípio educativo poderia ser a base de uma estratégia político-educativa revolucionária, 
tendo em vista que o trabalho, no capitalismo, se caracteriza como forma destrutiva do gênero humano e de negação da condição da natureza humana. Assim, para esta perspectiva, o princípio educativo deveria ser a crítica radical do trabalho, no interior da crítica radical do capital e do capitalismo. Já Lessa $(2007)^{3}$ contesta a formulação de Saviani (2005), alegando que, para este último, a educação é o mesmo que trabalho.

As divergências ultrapassam o princípio educativo e chegam até os conceitos e tipos da educação emancipatória. Para Sousa Junior (1999), os dois conceitos mais tratados no campo marxista seria o de omnilateralidade e o de politecnia. Contudo, a omnilateralidade seria a formação humana prevista em Marx de todas as capacidades humanas, que não pode ser alcançada nos limites do capitalismo, fundado sob a divisão do trabalho, mas apenas no interior do socialismo, no qual o homem poderia desenvolver todas suas potencialidades. Já a politecnia seria a noção marxista afeta ao interior do capitalismo, no qual o trabalhador seria preparado tanto para os aspectos técnicos, como para os aspectos críticos, sociais e políticos para superar o capitalismo. Concorda com esta conceituação Kuenzer (2001), acrescentando que a politecnia seria, na tradição marxista, a formação de uma sólida formação cultural, diversa da simples erudição, ou seja, seria a síntese superadora dos limites da divisão do trabalho, reunificando o trabalho intelectual (academicismo clássico) e o instrumental (profissionalização estreita). Para Saviani (2003), trata-se, ainda, a politecnia, do resgate da relação entre conhecimento, trabalho e relações sociais, por meio da apropriação do conhecimento científico-tecnológico e de uma perspectiva histórico-crítica. Kuenzer (2001) destaca, ainda, a necessidade da politecnia, enquanto conteúdo, vir acompanhada também da escola unitária, como estrutura educacional, na tradição gramsciana e da dialética, enquanto método de ensino.

Por outro lado, Nosella (2007) discorda da utilização semântica do termo politecnia, recorrendo-se a Marx, Lenin, Gramsci e Mario Manacorda. Para Nosella (2007), o termo é impróprio, pois, em Marx, o termo melhor cunhado seria o da educação tecnológica, já que o termo politecnia estaria mais relacionado ao contexto da formação de várias técnicas, na educação capitalista, ainda que este termo tenha sido mais largamente utilizado depois de Lenin. Politecnia, para Nosella (2007), surgiria no dicionário como sinônimo de polivalente, portanto, se tornaria semanticamente arbitrária a distinção dos autores do trabalho e educação entre estes dois termos, um caracterizado como do campo do capital e outro do trabalho.

\section{Trabalho e educação: contribuições para a educação física brasileira}

Desde o começo dos anos 2000, há uma tendência crescente na produção do conhecimento da educação física brasileira, no que diz respeito ao interesse nos estudos sobre as mudanças no mundo do trabalho e o reordenamento do trabalho do professor. A produção de pesquisas a respeito desta temática concentra-se, sobretudo, em teses e dissertações. Outros frutos desta produção são alguns artigos que já começam a ser publicados nos principais periódicos e eventos. São, em sua essência, trabalhos que problematizam o trabalho pedagógico na tradicional área escolar, bem como nos diversos campos de trabalho não escolares. 
É possível afirmar, por outro lado, que as contribuições do campo trabalho e educação para a educação física brasileira surgiram em temáticas diversas do estudo do reordenamento do trabalho do professor de educação física, ainda no final do século XX. Estas contribuições foram buscadas para dar respostas no interior da disputa entre setores conservadores/corporativistas e setores progressistas/revolucionários pela direção ou condução teórico-política da área, ${ }^{4}$ convergidas nas temáticas da formação profissional e a regulamentação da profissão.

A implantação generalizada do neoliberalismo, desde os anos 1980, trouxe a desobrigação do Estado com a gerência das conquistas sociais e, no caso norteamericano, uma proliferação de serviços privados no setor da saúde, entre eles, o das academias de ginástica. Ainda que o Brasil não vivesse, à época, a implantação do neoliberalismo, acompanhou o crescimento das academias de ginástica que, somando-se à tradição esportiva e do lazer, começou a apontar novos campos de atuação do professor de educação física, que até então se concentrava, em grande expressão, no trabalho escolar. Assim, o campo conservador/corporativista já ensaiava, ainda sem muito logro, a defesa, tanto da reserva dos campos de trabalhos emergentes por meio da regulamentação da profissão como a formação específica do professor por intermédio da criação do bacharelado. São, portanto, discussões mediadas pela saída estratégica da área junto à crise do capital e a sua forma gerencial.

É possível afirmar que tais discussões podem ser divididas, historicamente, em duas fases, conforme a implantação dos projetos políticos na área. A primeira fase compreendeu, essencialmente, a década de 1980, que findou com dois significativos marcos, um em 1987, com a aprovação da resolução 03/87 do Conselho Federal de Educação, que instituía, pela primeira vez, a modalidade do bacharelado nos cursos de formação, e o outro em 1989, quando ocorreu o veto presidencial de José Sarney ao Projeto de Lei 4559/84, do deputado Darci Pozza, primeiro projeto para a regulamentação da profissão de educação física.Tanto a regulamentação da profissão como o bacharelado não obtiveram êxito, posto que este último, na prática, não foi implementado em larga escala pelos cursos de formação. ${ }^{5}$ Assim, na década de 1980, apesar das investidas e avanços do grupo conservador/corporativista, estes não conseguiram concluir em sua plenitude seus projetos políticos, considerando-se ainda o ascenso dos movimentos sociais na educação física e a não implantação do neoliberalismo no país.

Se na década de 1980 os estudos marxistas concentraram-se nos aspectos filosóficos, históricos e pedagógicos, é justamente na segunda fase das discussões da formação profissional e da regulamentação da profissão,no final da década de 1990, que se iniciaram os estudos que abordavam o trabalho do professor de educação física. Nesta segunda fase, já em plena implantação do neoliberalismo no país, o grupo conservador/corporativista conseguiu duas grandes vitórias em seu projeto hegemônico: a aprovação da Lei 9696/98, da regulamentação da profissão, e a aprovação da Resolução 07 de 2004 do CES/CNE, novas Diretrizes Curriculares da área, que manteve a fragmentação, agora denominada de licenciatura e graduação.

Ainda é cedo para que se possa afirmar que ambos os projetos conseguiram se consolidar no seio da educação física, no entanto, é possível considerar que, com- 
parativamente à década posterior, os anos de 1990 trouxeram grandes vitórias para o setor conservador/corporativista. Para promover um combate ao avanço das políticas conservadoras na área e a defesa de um projeto emancipador, o setor revolucionário, agora também desvinculado do setor progressista, protagonizou a defesa contrária à regulamentação da profissão e a defesa da formação unificada. Esta é, de fato, a materialidade dos estudos dos anos 1990, que deu início às pesquisas que investigam o trabalho do professor de educação física. Os estudos a respeito da formação profissional e da regulamentação da profissão partiam por diversas vezes das análises das mudanças do mundo do trabalho que tinham como manifestação o desemprego, a precarização e a intensificação do trabalho mundial, seguindo a esteira do campo trabalho e educação. Começaram a apontar que havia, também, a mudança do conteúdo do trabalho do professor de educação física, saindo da escola e abarcando os campos não escolares que, no entanto, diferentemente do que alardeava a apologia liberal da área, eram campos caracterizados por uma grande precarização.

Assim, é justo afirmar que os estudos marxistas dos anos de 1990, que se dedicaram ao exame da formação profissional e da regulamentação da profissão, foram precursores e ainda fazem várias correlações com os estudos das mudanças e caracterização contemporânea do trabalho do professor de educação física. Neste ponto, houve a necessidade da recuperação do exame da categoria trabalho, categoria central para o marxismo. Assim, tais estudos começaram a se apoiar em áreas de referência ainda novas para a produção de conhecimento da área, a sociologia do trabalho e o trabalho e educação.

A respeito dos estudos do trabalho executado pelo professor de educação física, ainda que o trabalho nos campos não escolares - academias, clubes, hotéis, espaços de lazer, entre outros - não se trate de apenas um único, mas de vários campos de trabalho, é possível identificar, desde os anos de 1980, que a educação física viria a tratar, fundamentalmente, de uma dupla de campos, escolar e não escolar, que, por vezes, acabam sendo apontados como antagonistas no que diz respeito à projetos político-pedagógicos.

\section{Trabalho e educação física: formação de um novo campo de estudo?}

A primeira década dos anos 2000, ainda sob a mesma materialidade histórica das décadas anteriores, presenciou o surgimento e o crescimento dos estudos sobre o mundo do trabalho e a educação física. Um estudo inicial que abordou esta temática foi o de Nozaki (2004) que, contudo, ainda tratava-se de um trabalho que problematizava a regulamentação da profissão. Não obstante, algumas análises de sua investigação parecem guiar os posteriores estudos sobre o trabalho do professor de educação física, entre elas: a) a educação física ligou-se historicamente à formação do corpo disciplinado e subordinado a repetições de exercícios que não é mais central para a demanda da formação do trabalhador de novo tipo, calcado nas competências com forte conteúdo cognitivo e interacional; b) na proporção em que a educação física parece não atuar diretamente para a formação de competências, não se torna imediatamente central na escola, tornando-se marginal e secundarizada sob o ponto de vista imediato, porém, 
integrando o projeto dominante de forma mediata, tornando-se um artigo de luxo a ser consumido em escolas destinadas à burguesia ou às camadas mais elevadas da classe trabalhadora; c) por outro lado, por meio da noção de empreendedorismo, o professor de educação física foi vislumbrando a possibilidade de atuação nos campos não escolares, caracterizados pela precarização do trabalho enquanto fenômeno de gerência da crise do capital; d) o que é estratégia de gerência da crise do capital se torna um atrativo para a venda da força de trabalho por parte do professor.

Seguindo a linha de estudos sobre as modificações no mundo do trabalho e as implicações na educação física, pode-se apontar a dissertação de Santos (2005) que, ao analisar as implicações da pedagogia das competências para a educação física, evidenciou o deslocamento da formação para o trabalho, privilegiada pela perspectiva taylorista/fordista para a formação para a vida no trabalho abstrato, necessidade do padrão de acumulação toyotista e projeto a ser assegurado pela pedagogia das competências. Neste sentido, Santos (2005) demonstrou uma mediação da educação física não só no projeto pedagógico para as elites brasileiras, porém, também encontrada na escola pública, quando esta formaria não a dimensão cognitiva, mas padrões de comportamentos, tais como a resolução de problemas, tomadas de decisões, importantes para a conformação do novo tipo de trabalhador, com valores tais como coletividade, cooperação, solidariedade e trabalho em grupo.

Já os estudos do trabalho do professor de educação física são mediados pela discussão em torno dos campos de atuação. É possível identificar as investigações neste campo em duas grandes linhas, a da escola e a dos campos não escolares, estes últimos com forte concentração nas academias de ginástica. Um primeiro autor que se dedicou aos estudos voltados para as academias de ginástica foi Furtado (2007). Na sua dissertação de mestrado, que reúne análises de seus estudos anteriores, o autor investiga a organização do trabalho nas academias de ginástica e a inserção do professor de educação física. Encontra como resultados a transformação da cultura corporal em mercadorias vendidas na academia de ginástica. Salienta ainda que, com o desenvolvimento do segmento fitness no Brasil, ocorreu um processo de diversificação da gerência administrativa das academias, combinando-se a coexistência do mais desenvolvido padrão administrativo com a de menor tecnologia e racionalização. Sob o ponto de vista da organização do trabalho do professor, encontrou um papel fundamentalmente gerencial, de um professor vendedor de mercadorias, que atua na perspectiva de um duplo movimento nas academias de ginástica: o primeiro, de recepção, atração e venda dos produtos; e o segundo, de produção, conquista e venda da cultura corporal transformada em mercadorias.

No campo, portanto, dos estudos voltados às academias de ginástica, é possível apontar dois enfoques centrais: o da gestão das academias e o do trabalho do professor. Um estudo sobre a gestão das academias que merece destaque é o de Vivan (2010), que procurou investigar tendências de desenvolvimento no setor fitness e wellness no país. A partir da compreensão de que o desenvolvimento nestes setores se insere no interior do desenvolvimento do setor de serviços no capitalismo monopolista, obedecendo, portanto, à lógica da concorrência intercapitalista, a dissertação de Vivan (2010) revela os mecanismos de atração e retenção de consumidores, bem como os 
processos de monopolização, terceirização, franquia, massificação, segmentação, obsolescência planejada destes setores.

Representando o outro enfoque, o do trabalho do professor de educação física nas academias de ginástica, destacam-se as dissertações de Both (2009) e de Coimbra (2009). Ambas as pesquisas analisam o trabalho nos campos não escolares e revelam dados da precarização e intensificação do trabalho do professor de educação física. Estes estudos são reveladores no que diz respeito à crítica a apologia de que os campos não escolares seriam a solução para a crise do trabalho abstrato no campo escolar. Os campos não escolares são apontados, nestas pesquisas, como permeados de contradição e características tais como a desregulamentação do trabalho, o trabalho em vários locais (academias ou similares) para compor o rendimento mensal, o pequeno tempo de vida no trabalho, o desgaste físico, cansaço, lesões e extensas jornadas de trabalho.

Um estudo, recentemente finalizado, é a tese de doutorado de Quelhas (2012), que elabora síntese das discussões entre a gerência das academias de ginástica e o trabalho do professor de educação física em seu interior. Reunindo a produção sobre esta temática anteriormente espalhada e situando-a no contexto de ser o Brasil um recordista da desregulamentação do trabalho no começo do século XXI, Quelhas (2012) evidencia a precarização do trabalho no segmento fitness por meio do piso salarial e do número reduzido de aulas que os professores conseguem assegurar em cada academia de ginástica. Os professores que atuam em regime horista tendem a ganhar menos que um salário mínimo, porém, há uma justificativa à exploração por conta de supostas compensações a partir do trabalho como personaltrainner. Contudo, para a empresa que o contrata, há apenas o movimento de ampliação da retirada da mais-valia deste trabalhador, posto que, tanto do lado do assalariamento como do lado da contratação terceirizada, a empresa ganha, seja pela extração direta da mais-valia, seja pela desobrigação dos encargos contratuais. Ainda, os dados revelados por Quelhas (2012) orientam as análises de que este setor tende à monopolização, sobretudo de grandes corporações do fitness, deixando cada vez mais para trás a visão romântica de que o professor formado em educação física começaria seu próprio negócio, empreendendo a abertura de uma academia de ginástica e gerenciando-a, a partir do seu próprio labor. Vale mencionar, na esteira do artigo de Dias (2010), que retoma sua dissertação de mestrado (DIAS, 2006), para refletir o movimento de empreendedorismo na educação física brasileira, que este tem adentrado a área por meio de um discurso que abarca duas formas: na escola, por meio de uma perspectiva pedagógica voltada para a formação de uma ética empreendedora, e nos campos não escolares, visando à criação do próprio negócio como as academias de ginástica, musculação, entre outros.

Já a investigação do campo escolar é mais tradicional na educação física. Os estudos que pesquisam a articulação da educação física com o projeto de formação humana dominante constatam, a partir do chão da escola, que desde os anos 1990, ocorre uma inferiorização da educação física na escola (JEBER, 1996), fruto da permanência do modelo de formação humana voltada para o antigo padrão produtivo, o modelo taylorista/fordista, o que justifica a secundarização desta disciplina para o projeto de formação do trabalhador de novo tipo. Seriam eles elementos ligados à perspectiva pe- 
dagógica da década de 1970, da aptidão física, com predominância do conteúdo esporte, em sua dimensão técnica, enfatizando-se a repetição mecânica, com estafetas, sem a continuidade ou progressão dos fundamentos ensinados durante as séries. Andrade (2001) apontou a desvalorização da educação física, posto que esta não é vista enquanto possuidora de conhecimento, mas tratada como uma disciplina folgadora, uma atividade compensatória do esforço realizado pelas demais disciplinas. Andrade (2001) evidenciou a subordinação da educação física a outras disciplinas quando encontrou depoimentos que ressaltavam a possibilidade de ela trabalhar conteúdos de outras áreas, tais como a matemática, como forma de reforço escolar. De outro modo, foram citadas como disciplinas centrais, pelos entrevistados da pesquisa - alunos, professoras e diretoras -, justamente aquelas que vêm sendo consideradas importantes para a formação do trabalhador, a partir dos modelos das competências, como a matemática, a língua portuguesa, a língua estrangeira e a informática. Neste contexto, conclui a autora que os alunos colocam a educação física em segundo plano, tendo em vista a priorização de sua formação para a sobrevivência e manutenção por meio do trabalho.

Os estudos do campo escolar, no entanto, não possuem, em sua maioria, um enfoque nos estudos do trabalho. Neste campo, os estudos referem-se, essencialmente, àqueles que dão atenção ao trabalho pedagógico da educação física, a partir do referencial trazido da área educacional (FREITAS, 1995). Neste sentido, Taffarel (2010) ressalta que a sociedade capitalista aprofunda a divisão do trabalho escolar, sobretudo por meio do tecnicismo e da introdução do gerenciamento científico na escola, baseado na mesma perspectiva do mundo da produção, ou seja, alienação da concepção e processo do trabalho para controle do trabalhador. O professor fica, desta forma, apartado dos processos de planejamento, execução e avaliação contínua do processo de ensino. Já Paraíso (2011) estuda as possibilidades de organização do trabalho pedagógico da ginástica escolar, empreendendo análise bibliográfica de quatro propostas de ensino da ginástica na escola. Destaca, em seu estudo, que, para a reorganização do trabalho pedagógico na escola, são necessárias a interação e articulação de princípios, tais como: trabalho como princípio educativo e a auto-organização e autodeterminação dos estudantes. Conclui que é necessária uma relação dialética entre projeto histórico, teoria educacional, teoria pedagógica e organização do trabalho pedagógico.

Uma pesquisa da área escolar que levantou questões propriamente ditas do trabalho do professor foi a de Magalhães e Martinelli (2011) que, ao aplicar questionário semiaberto a 52 professores da rede estadual de Maringá (PR), levantou dados tais como: a) o tempo e local(is) de trabalho(s); b) formação acadêmica; c) campo de trabalho pretendido e exercido; d) identidade com a educação física escolar; e) dificuldades enfrentadas no início da carreira e problemas da atualidade; f) possibilidades de superação dos problemas do cotidiano escolar; e, g) perspectivas de estudos. Encontraram como resultados principais os problemas destacados pelos professores, tais como a desvalorização profissional, a estrutura física da escola, a gestão/administração escolar e governamental e as dificuldades no âmbito didático pedagógico e de formação de professores. As categorias sistematizadas pelos autores para a análise das respostas dadas pelos professores foram: a) políticas públicas de formação continuada; b) atualização, cursos e projetos; c) organização coletiva do trabalho pedagógico; d) legitimidade da educação física; e) políticas públicas de investimento; f) participação dos alunos e da família; e g) recursos materiais. 
Os estudos do trabalho do professor de educação física têm ocupado atenção junto aos meios de publicação da área. A revista Motrivivência publicou, em dois números seguidos (REVISTA MOTRIVIVÊNCIA 2010; 2011), temática relacionada ao mundo do trabalho e a educação física. ${ }^{6}$ Abaixo, sistematiza-se a incidência dos estudos contidos nestas duas edições:

Quadro 1: estudos relacionados às mudanças do mundo do trabalho e o trabalho do professor de educação física

\begin{tabular}{|l|l|}
\hline \multicolumn{1}{|c|}{ Temática } & \multicolumn{1}{c|}{ Trabalho } \\
\hline $\begin{array}{l}\text { Pedagogia das competências e educação } \\
\text { física }\end{array}$ & Santos (2010) \\
\hline Empreendedorismo e educação física & Dias (2010) \\
\hline $\begin{array}{l}\text { Organização do trabalho pedagógico na } \\
\text { escola }\end{array}$ & $\begin{array}{l}\text { Taffarel (2010) } \\
\text { Paraíso (2011) }\end{array}$ \\
\hline Trabalho do professor na escola & Magalhães e Martinelli (2011) \\
\hline $\begin{array}{l}\text { Precarização do trabalho docente do ensino } \\
\text { superior }\end{array}$ & Cunha (2010) \\
\hline Empresariamento das academias & $\begin{array}{l}\text { Coimbra (2010) } \\
\text { Quelhas (2011) }\end{array}$ \\
\hline $\begin{array}{l}\text { Trabalho do professor de EF em campos } \\
\text { não escolares }\end{array}$ & $\begin{array}{l}\text { Both (2011) } \\
\text { Quelhas (2011) } \\
\text { Guimarães Filho, Moura e Antunes (2011) }\end{array}$ \\
\hline
\end{tabular}

Quadro 2: estudos correlacionados às questões do trabalho e educação física

\begin{tabular}{|l|l|}
\hline \multicolumn{1}{|c|}{ Temática } & \multicolumn{1}{c|}{ Trabalho } \\
\hline Formação de professores & $\begin{array}{l}\text { Cruz (2011) } \\
\text { Dias e Teixeira (2010) } \\
\text { Sobrinho (2011) }\end{array}$ \\
\hline Regulamentação da profissão & Silva e Frizzo (2011) \\
\hline Lazer & $\begin{array}{l}\text { Cândido e Jinkings (2010) } \\
\text { Peixoto (2010) }\end{array}$ \\
\hline Trabalho no campo & Dalmagro e Vendramini (2010) \\
\hline Cultura corporal e currículo escolar & $\begin{array}{l}\text { Teixeira e Dias (2011) } \\
\text { Macieira, Mata e Herminda (2011) }\end{array}$ \\
\hline
\end{tabular}

Quadro 3: estudos sobre a categoria trabalho

\begin{tabular}{|l|l|}
\hline \multicolumn{1}{|c|}{ Temática } & \multicolumn{1}{c|}{ Trabalho } \\
\hline Categoria trabalho & Antunes (2010) \\
\hline Ontologia do ser social & Ortigara (2011) \\
\hline
\end{tabular}




\section{Trabalho e educação física: tendências e perspectivas}

Ao realizar esta primeira análise sobre os estudos do trabalho e educação física, é possível constatar o que tem de comum nestes estudos, além do referencial marxista. É justamente a centralidade da categoria trabalho, em sua condição ontológica, de existência humana e sua descaracterização a partir da divisão do trabalho, o trabalho abstrato na sociedade capitalista. Textos tais como o de Antunes (2010) e Ortigara (2011) buscam aprofundar a categoria trabalho e a sua condição ontológica. Por outro lado, os demais estudos aqui citados, seja abordando ou não, diretamente, o trabalho do professor de educação física, apreendem análises acerca da reconfiguração do mundo do trabalho, em razão da gerência da crise estrutural do capital e das demandas para o campo educacional, em geral, e da educação física, em particular.

No país, o que sustenta a produção dos estudos do trabalho e educação física são fundamentalmente as produções, em nível de pós-graduação (mestrado e doutorado), sobretudo concentradas em programas da educação, muitos deles com o enfoque no campo trabalho e educação. Não se observa a consolidação destes estudos nos programas de pós-graduação em educação física. Por outro lado, alguns grupos de pesquisa, tais como o Grupo de Estudos do Trabalho, Educação Física e Materialismo Histórico (GETEMHI), de Juiz de Fora (MG), e a Linha de Estudos e Pesquisa em Educação Física \& Esporte e Lazer (LEPEL), de Salvador (BA) e outras cidades, têm sustentado a produção nesta área. Destaca-se, ainda, que esta discussão vem ganhando espaço nos meios de publicação da área, tais como o exemplo analisado aqui dos dois números da Revista Motrivivência. Ainda, alguns eventos, tais como o IV Seminário de Epistemologia em Educação Física, organizado pela Linha de Estudos Epistemológicos e Didáticos em Educação Física (LEDEEF), da UFSM, em 2013, procuram promover diálogo entre o campo Trabalho e Educação e os estudos voltados à educação física.

Levando em consideração este estado da arte inicial sobre os estudos do trabalho e educação física, é possível afirmar que ainda é cedo para constatar a constituição e consolidação de um novo campo de estudo, ainda que se indique a tendência à sua formação nos próximos anos. Os estudos atuais sobre o trabalho do professor de educação física procuram unificar os dois campos, escolar e não escolar em um único objeto, o do trabalho abstrato em uma sociedade produtora de mercadorias. Assim, mais importante do que conceber, de forma pseudoconcreta, que a disputa entre as visões de mundo estão simplesmente materializadas em campo escolar e não escolares, é necessário compreender o objeto do trabalho do professor de educação física em uma totalidade concreta, com as mediações do sistema capitalista de produção atuando em seus vários campos de atuação.

\section{Referências}

ANDERSON, P. Balanço do neoliberalismo. In: SADER, E.; GENTILI, P. (Org.). Pós-neoliberalismo. As políticas sociais e o estado democrático. São Paulo: Paz e Terra, 1995. p. 9-23. 
ANTUNES, R. L.Adeus ao trabalho?: ensaio sobre as metamorfoses e a centralidade do mundo do trabalho. 3 ed. São Paulo: Cortez, 1995.

. Os sentidos do trabalho: ensaio sobre a afirmação e a negação do trabalho. São Paulo: Boitempo Editorial, 1999.

ALVES, G. O novo (e precário) mundo do trabalho: reestruturação produtiva e crise do sindicalismo. São Paulo: Boitempo, 2000.

ANDRADE, M. A. B. O descaso com a educação física e o reordenamento no mundo do trabalho. Monografia de Especialização. Juiz de Fora: UFJF, 2001.

ANTUNES, C. Acerca da indissociabildiade entre as categorias trabalho e educação. Revista Motrivivência, ano XXII, n. 35, p. 41-61, dez., 2010.

BAZÍLIO, L. C. Processo e relações de trabalho no banco verde. 1993. 310f. Tese (Doutorado Ciências Sociais) - Universidade Estadual de Campinas - Campinas: UNICAMP, 1993.

BIHR, A. Da grande noite à alternativa: o movimento operário europeu em crise. 2 ed. São Paulo: Boitempo, 1998.

BOTH, V. J. Mudanças no mundo do trabalho e suas mediações na educação física. 106f. Pelotas, 2009. Dissertação (Mestrado). Universidade Federal de Pelotas - Pelotas: UFPel, 2009.

Crise estrutural do capital, mudanças no mundo do trabalho e suas mediações na educação física. Revista Motrivivência, ano XXIII, n. 36, p. 45-62, jun., 2011.

CÂNDIDO, F. P.; JINKINGS, N. Reestruturação produtiva e investigação do lazer como mercadoria. Revista Motrivivência, ano XXII, n. 35, p. 79-98, dez., 2010.

COIMBRA, T. C. O reordenamento no mundo do trabalho e a precarização do trabalho do professor de educação física: mediações da mercadorização da cultura corporal. 2009. $177 f$. Dissertação (Mestrado em Educação) - Universidade Federal Fluminense, Niterói: 2009.

O reordenamento do trabalho do professor de educação física e a organização empresarial do âmbito fitness: CONFEF/CREF, ACAD e SINDACAD. Revista Motrivivência, ano XXII, n. 35, p. 62-78, dez., 2010.

CRUZ, A. O embate de projetos na formação de professores de educação física: além da dualidade licenciatura-bacharelado. Revista Motrivivência, ano XXIII, n. 36, p. 24-44, jun., 2011.

CUNHA, F. J. de P. Precarização do trabalho e educação física: situando a questão. Revista Motrivivência, ano XXII, n. 35, p. 113-129, dez., 2010.

DALMAGRO, S. L.; VENDRAMINI, C. R. O trabalho no campo e no contexto do MST. Revista Motrivivência, ano XXII, n. 35, p. 130-146, dez., 2010.

DIAS, F. B. M. D.; TEIXEIRA, D. R. Formação de professores de educação física: a atualidade do embate político. Revista Motrivivência, ano XXII, n. 35, p. 184-201, dez., 2010.

DIAS, G. P. Empreendedorismo e educação: o SEBRAE na escola. 2006. Dissertação (Mestrado em Educação)-Universidade Federal Fluminense, Niterói, 2006.

Empreendedorismo e educação física: reflexões à sua apreensão/implementação na formação humana. Revista Motrivivência, ano XXII, n. 35, p. 147-165, dez., 2010.

FREITAG, B. Escola, estado e sociedade. 6 ed. São Paulo: Moraes, 1986.

FREITAS, L. C. de. Crítica da organização do trabalho pedagógico e da didática. Campinas: Papirus, 1995.

FRIGOTTO, G. A produtividade da escolaimprodutiva. 3 ed. São Paulo: Cortez, 1989. 
FRIGOTTO, G. Os delírios da razão: crise do capital e metamorfose conceitual no campo educacional. In: GENTILI, P. (Org.). Pedagogia da exclusão: o neoliberalismo e a crise da escola pública. Petrópolis: Vozes, 1995. p. 77-108.

FURTADO, R. P. O não-lugar do professor de educação física em academias de ginástica. 2007. 186f. Dissertação (Mestrado em Educação)-Faculdade de Educação, Universidade Federal de Goiás, Goiânia, 2007.

GALVAN, C. G. É possível uma economia da educação? (Uma nota crítica sobre como "capital humano" e sua teorização escondem o real: o "trabalho humano"). Educação e Sociedade, v. 2, n. 2, 1979.

GOUNET, T. Fordismo e toyotismo na civilização do automóvel. São Paulo: Boitempo Editorial, 1999.

GUIMARÃES FILHO, J. C. de M.; MOURA, D. L.; ANTUNES, M. M. Quando a beleza põe mesa: uma análise das condições de trabalho do profissional de educação física em mega-academias. Revista Motrivivência, ano XXIII, n. 36, p. 197-213, jun., 2011.

HARVEY, D. Condição pós-moderna: uma pesquisa sobre as origens da mudança cultural. São Paulo: Edições Loyola, 1992.

JEBER, L. J. A educação física no ensino fundamental: o lugar ocupado na hierarquia dos saberes escolares. 1996. 173f. Dissertação (Mestrado em Educação)-Universidade Federal de Minas Gerais, Belo Horizonte, 1996.

KUENZER, A. Z. Pedagogia da fábrica: as relações de produção e a educação do trabalhador. São Paulo: Cortez, Autores Associados, 1986.

Ensino do $2^{\circ}$ grau: o trabalho como princípio educativo. 4 ed. São Paulo: Cortez, 2001.

LESSA, S. Trabalho e proletariado no capitalismo contemporâneo. São Paulo: Cortez, 2007.

MACIEIRA, J. A.; MATA, Á. A. R.; HERMINDA, J. F. A cultura corporal como objeto de estudo nos referenciais curriculares do ensino fundamental da Paraíba. Revista Motrivivência, ano XXIII, n. 36, p. 111-128, jun., 2011.

MAGALHÃES; C. H. F.; MARTINELI, T. A. P. Soluções formais no enfrentamento dos problemas da prática escolar. O estranhamento dos professores de educação física escolar. Revista Motrivivência, ano XXIII, n. 36, p. 214-235, jun., 2011.

MANFREDI, S. M. Trabalho, qualificação e competência profissional - das dimensões conceituais e políticas. Educação \& Sociedade: revista quadrimestral da Ciência da Educação/Centro de Estudos Educação e Sociedade (Cedes), Campinas, ano XIX, n. 64, p. 13-45, Set. 1998.

MARX, K. O 18 de Brumário de Luís Bonaparte. São Paulo: Boitempo, 2011.

NOSELLA, P. Trabalho e perspectivas de formação dos trabalhadores: para além da formação politécnica. Revista Brasileira de Educação. v. 12, n. 34, p. 137-181, jan./abr., 2007.

NOZAKI, H. T. Educação física e reordenamento no mundo do trabalho: mediações da regulamentação da profissão. 2004. 368f. Tese (Doutorado em Educação)-Universidade Federal Fluminense, Niterói, 2004.

Mudanças no mundo do trabalho e reordenamento do trabalho do professor de educação física. Lecturas Educación Física y Deportes, v. 123, p. 1-10, 2008.

ORTIGARA, V. Movimento humano, ontologia do ser social e educação física. Revista Motrivivência, ano XXIII, n. 36, p. 63-74, jun., 2011.

PARAÍSO, C. S. O trato com o conhecimento da ginástica: um estudo sobre possibilidades de superação. Revista Motrivivência, ano XXIII, n. 36, p. 169-196, jun., 2011. 
PEIXOTO, E. M. de M. Fundamentos marxistas: modo de produção como eixo para uma síntese em perspectiva histórica da relação Trabalho/Educação Física, Esportes e Lazer. Revista Motrivivência, ano XXII, n. 35, p. 99-112, dez., 2010.

POCHMANN, M. O trabalho sob fogo cruzado: exclusão, desemprego e precarização no final do século. São Paulo: Contexto, 1999.

QUELHAS, A. de A. Do currículo mínimo às Diretrizes Curriculares Nacionais: 30 anos de licenciatura em educação física na UFJF. In: CUNHA JÚNIOR, C. F. F. da, MARTIN, E. R. H.; ZACARIAS, L. dos S. (Org.). Educação física: narrativas e memórias em Juiz de Fora. Juiz de Fora: UFJF, 2003.

. Profissional de educação física no segmento fitness: reflexões a partir da categoria trabalho. Revista Motrivivência, ano XXIII, n. 36, p. 75-93, jun., 2011.

Trabalhadores de educação física no segmento fitness: um estudo da precarização do trabalho no Rio de Janeiro. 2012. 242f. Tese (Doutorado em Ciências Sociais)-Universidade Estadual Paulista, Marília, 2012.

RAMOS, M. N. A pedagogia das competências: autonomia ou adaptação? São Paulo: Cortez, 2001.

REVISTA MOTRIVIVÊNCIA. Florianópolis. ano XXII, n. 35, 201p., dez., 2010.

Florianópolis. ano XXIII, n. 36, 235p, jun., 2011.

RODRIGUES, J. O moderno príncipe industrial: o pensamento pedagógico da Confederação Nacional da Indústria. Campinas: Autores associados, 1998.

ROSSI, W. G. Capitalismo e educação: contribuição ao estudo crítico da economia da educação capitalista. 2 ed. São Paulo: Moraes, 1980.

RUMMERT, S. M. Educação e identidade dos trabalhadores: as concepções do capital e do trabalho. São Paulo: Xamã, Niterói: Intertexto, 2000.

SALM, C. Escola e trabalho. São Paulo: Brasiliense, 1980.

SANTOS, M. S. dos. Reordenamento do mundo do trabalho e pedagogia das competências: implicações para a educação física escolar. 2005. 112f. Dissertação (Mestrado em Educação)-Universidade Federal Fluminense, Niterói, 2005.

. Reordenamento do mundo do trabalho e pedagogia das competências: implicações para a Educação Física escolar (período pós 1990). Revista Motrivivência, ano XXII, n. 35, p. 166183, dez., 2010.

SAVIANI, D. Escola e democracia. 7 ed. São Paulo: Cortez: Autores Associados, 1985.

. O choque teórico da politecnia. Trabalho, Educação e Saúde, Rio de Janeiro, v. 1, n. 1, p. 131-152, mar. 2003. ciados, 2005.

Pedagogia histórico - crítica: primeiras aproximações. 9 ed. Campinas: Autores Asso-

SOUSA JUNIOR, J. de. Politecnia e onilateralidade em Marx. Trabalho e Educação: Revista do NETE. Belo Horizonte, n.5, p.98-114, jan/jul., 1999.

SCHULTZ, T. O valor econômico da educação. Rio de Janeiro: Zahar Editores, 1967.

SILVA, G. G. da; FRIZZO, G. F. E. Crítica à regulamentação da profissão e à produção científica defensora do sistema CONFEF/CREFs. Revista Motrivivência, ano XXIII, n. 36, p. 149-168, jun., 2011.

SINGER, P. Globalização e desemprego: diagnóstico e alternativas. 4 ed. São Paulo: Contexto, 2000. 
SOBRINHO, J. P. S. Formação de professores na sociedade do capital: uma análise crítica das diretrizes curriculares nacionais para os cursos superiores de educação física. Revista Motrivivência, ano XXIII, n. 36, p. 129-148, jun., 2011.

TAFFAREL, C. Do trabalho em geral ao trabalho pedagógico: contribuições ao debate sobre o trabalho pedagógico na Educação Física. Revista Motrivivência, ano XXII, n. 35, p. 18-40, dez., 2010.

TEIXEIRA, D. R.; DIAS, F. B. M. A necessidade histórica da cultura corporal: limites e possibilidades sob a ordem capitalista. Revista Motrivivência, ano XXIII, n. 36, p. 94-110, jun., 2011.

TUMOLO, P. S. O significado do trabalho no capitalismo e o trabalho como princípio educativo: ensaio de análise crítica. Trabalho Necessário, ano 1, n. 1, 2003.

. O trabalho na forma social do capital e o trabalho como princípio educativo: uma articulação possível? Educação e Sociedade, v. 26, n. 9-, p. 239-265, jan-abr, 2005.

VASAPOLLO, L. O trabalho atípico e a precariedade. São Paulo: Expressão Popular, 2005.

VIVAN, R. P. Mercantilização das práticas corporais e metamorfoses no trabalho: um estudo sobre a indústria do fitness e bem-estar.2010. 102f. Dissertação (Mestrado em Educação)-Universidade Federal do Paraná, Curitiba. 2010.

\section{Notas}

${ }^{1}$ A intenção deste item é situar o surgimento e as contribuições do campo trabalho e educação para as análises das mudanças no mundo do trabalho e o confronto entre a perspectiva educacional capitalista e a socialista. Contudo, trata-se apenas de um mapeamento das discussões, sem a intenção de realizar uma revisão sistemática ou um estado da arte sobre a temática, tampouco explicitar o debate entre as terminologias pedagogia capitalista, pedagogia socialista, pedagogia hegemônica, pedagogia contra hegemônica, entre outras.

${ }^{2}$ Há contraposições entre os autores do campo trabalho e educação na utilização desses termos, os quais discorreremos mais à frente.

${ }^{3}$ Ainda que Sérgio Lessa não seja um autor do campo educacional, é bastante utilizado no campo trabalho e educação, por ter feito críticas aos estudos de Saviani, juntamente com os de Antunes e os de Marilda Iamamoto.

${ }^{4}$ Neste texto, trabalhar-se-á com a noção de dois grupos fundamentais na disputa política da educação física, sem deixar de admitir que esses dois grupos possuam diversas frações e tendências internas, inclusive que se diferenciam no horizonte teleológico da sociedade que querem construir. Uma análise mais detalhada destas divisões, na tradição em que Marx (2011) escreveu o XVIII de Brumário de Luiz Bonaparte, foge do intento deste estudo. Da mesma forma, vale a lembrança de que a disputa dos grupos antagonistas na educação física brasileira refere-se à própria disputa no interior da luta de classes, tese esta que não será possível ser desenvolvida nos limites deste artigo.

${ }^{5}$ Os dados levantados por Quelhas (2003) evidenciam que, em 1994, dos 128 cursos de formação em educação física, apenas 5 possuíam a formação de bacharelado.

${ }^{6}$ Para fins deste artigo, concentramos as análises nos dois números da Revista Motrivivência (2010, 2011), buscando ressaltar o empenho desta revista em tematizar estudos sobre o trabalho e a educação física, que poderia indicar uma tendência em focalizar tal temática na área. Outros periódicos não foram ressaltados aqui, pois, os artigos publicados ligados a esta temática são oriundos, na sua essência, das diversas teses, dissertações e monografias já citadas anteriormente. Para uma leitura de artigos sobre o trabalho do professor de educação física publicados em periódicos nacionais, consultar Nozaki (2008). 
Hajime Takeuchi Nozaki

* Professor Doutor da Universidade Federal de Juiz de Fora, Juiz de Fora, Minas Gerais, Brasil.

\section{Correspondência}

Hajime Takeuchi Nozaki - Universidade Federal de Juiz de Fora, Faculdade de Educação. São Pedro. CEP: 36036900 - Juiz de Fora, Minas Gerais, Brasil.

E-mail: hajimenozaki@uol.com.br

Recebido em 21 de março de 2013

Aprovado em 28 de agosto de 2014 